\title{
EDITORIAL
}

\section{Non-invasive mechanical ventilation in hematology patients with hypoxemic acute respiratory failure: a false belief?}

\author{
Bone Marrow Transplantation (2012) 47, 469-472; \\ doi:10.1038/bmt.2011.232
}

Acute respiratory failure (ARF) is the most frequent and challenging life-threatening event in patients with hematological malignancies. ${ }^{1}$ In patients with prolonged neutropenia, respiratory events occur in up to half the cases, of which half are complicated by ARF. ${ }^{2}$ Although significantly improved over the last two decades ${ }^{3-5}$ survival of hematology patients with ARF remains low, especially when mechanical ventilation is needed.

Non-invasive mechanical ventilation (NIV) successfully treats ARF in patients with hyperbaric chronic obstructive pulmonary disease exacerbation or cardiac pulmonary edema. ${ }^{6}$ NIV is helpful to reduce the need and complications from intubation and invasive mechanical ventilation. In addition, NIV has also been recommended in other clinical conditions such as hypoxemic ARF in immunocompromised patients. ${ }^{7}$ The benefit seems convincing in the postoperative setting of organ transplantation. ${ }^{8}$ However, only very few studies have actually demonstrated benefit in hematology patients. Most of these studies did not control time between ARF onset to NIV implementation, without taking into account ARF etiology, or the presence of associated organ dysfunction at the time of NIV initiation. ${ }^{9}$ As a consequence, prophylactic NIV (in patients with hypoxemia but no respiratory distress) and curative NIV (patients with respiratory distress needing ventilatory support) were lumped together (Table 1). Furthermore, chronic obstructive pulmonary disease and cardiac patients were included, as were patients with various ARF etiologies, some of which may respond better to NIV. These limitations add to safety concerns with the use of NIV in ARF patients who could benefit from early intubation and mechanical ventilation. ${ }^{10,11}$

A well-designed single center randomized controlled study of prophylactic NIV in hypoxemic immunocompromized patients (including 30 hematology patients) demonstrated highly significant benefit from NIV. ${ }^{12}$ As a striking finding in this study published 10 years ago, $90 \%$ of the patients intubated and $50 \%$ of the patients with NIV success died. Corresponding figures nowadays would be up to 60 and $15 \% .{ }^{13}$ Therefore, we are convinced that the current literature has witnessed important advances over the last decades, at a time where most of the hematology patients requiring intubation and mechanical ventilation were dying. However, we also believe that the same studies remain inconclusive now that a substantial number of patients survive to life-sustaining therapies, more particu- larly mechanical ventilation. Therefore, additional studies are warranted, more particularly in hematology patients, to appraise and update the literature. NIV should be compared with oxygen and early intubation when needed, a therapy that offers nowadays substantial chances of survival.

Table 1 summarizes results from studies that have evaluated NIV in cancer patients. Taken together, these studies suggest benefits from trials of prophylactic inintensive care unit (ICU) NIV in patients without extrarespiratory-associated acute organ dysfunctions. They also highlight the risk from late intubation, that is, after NIV failure. However, as shown in Figure 1, compiled data from the current literature does not enable us to draw any sound conclusion.

In the current issue of the Journal, Wermke ${ }^{14}$ reported a well-conducted trial of prophylactic NIV in hematology patients outside the ICU, in the BMT unit. This study has the strength of providing valuable information in a homogeneous group of patients with hypoxemia, without significant confounding morbidities, and with an unbiased use of the ICU or of mechanical ventilation. This study shows that NIV performed in the wards is ineffective in hypoxemic hematology patients with ARF. The negative results from this study have several explanations. (1) NIV can be considered as conclusively ineffective in hypoxemic ARF, even in hematology patients. This would be based on the lack of sufficient evidence in the literature and on a doubtful risk/benefit ratio at a time where mechanical ventilation is no longer constantly fatal, more particularly in patients with respiratory distress; (2) prophylactic (as opposed to curative) NIV may be ineffective in hematology patients. This finding needs to be considered as serious information as concerns have been raised about the use of NIV in patients with criteria for mechanical ventilation or associated organ dysfunction. ${ }^{15}$ (3) In hypoxemic ARF patients, NIV may be ineffective in the hematology wards. This would be related to the lack of tight monitoring by ICU nurses and availability of intensivists to make adequate and timely decisions at any time of the day or the night. Along this line, an Italian study in the hematology wards where nursing and medical teams had greater NIV experience and with strict intensivist supervision has shown that in patients with respiratory events and early changes in respiratory parameters, continuous positive airway pressure (CPAP) allowed significant reduction in ICU admission, mechanical ventilation and offered survival benefits. ${ }^{16}$ (4) When NIV is performed in the wards, timing for ventilatory support and ICU admission may be hampered by NIV itself. For instance, NIV may be 


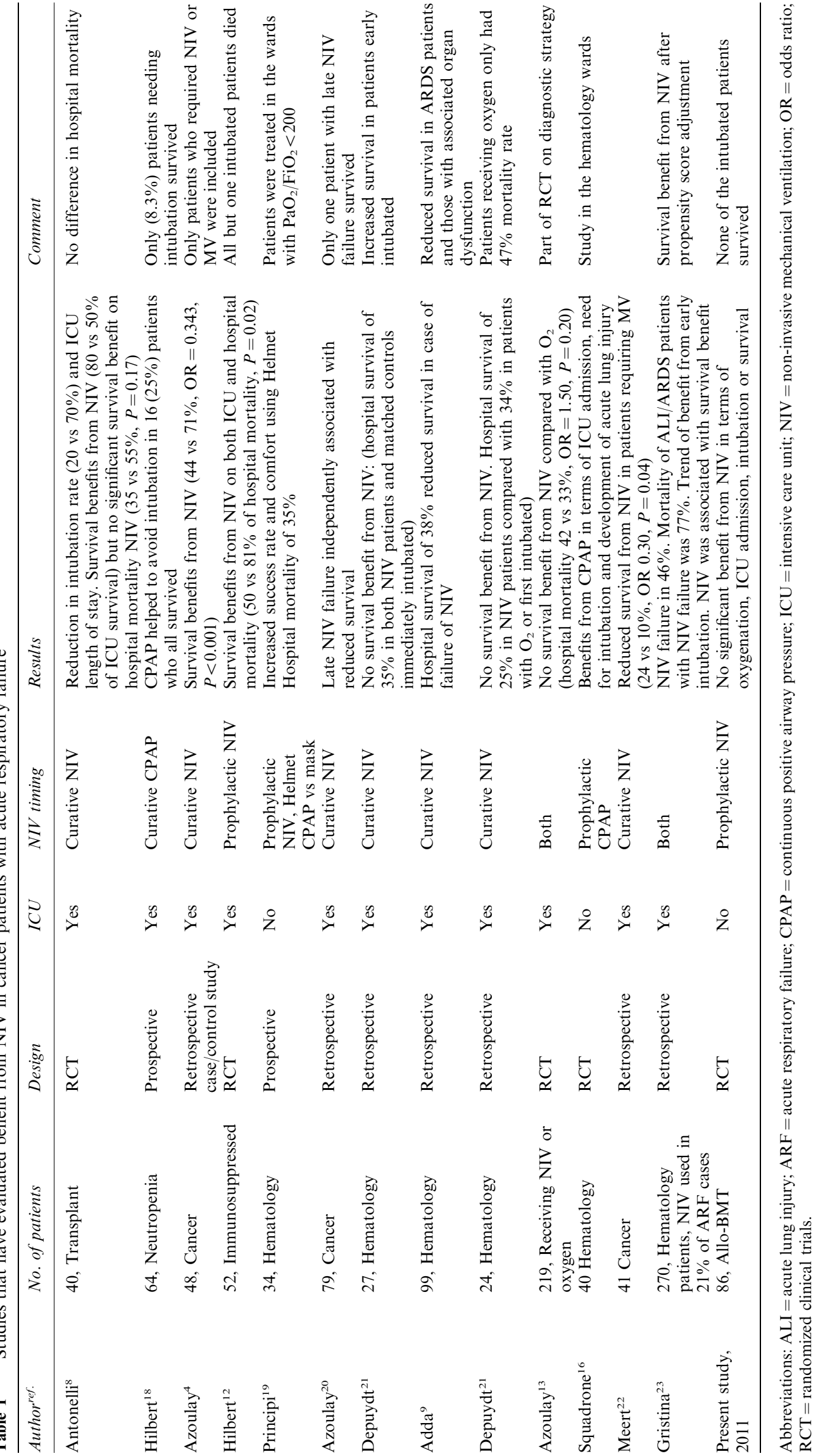


Study reference (no. 02/No. NIV)

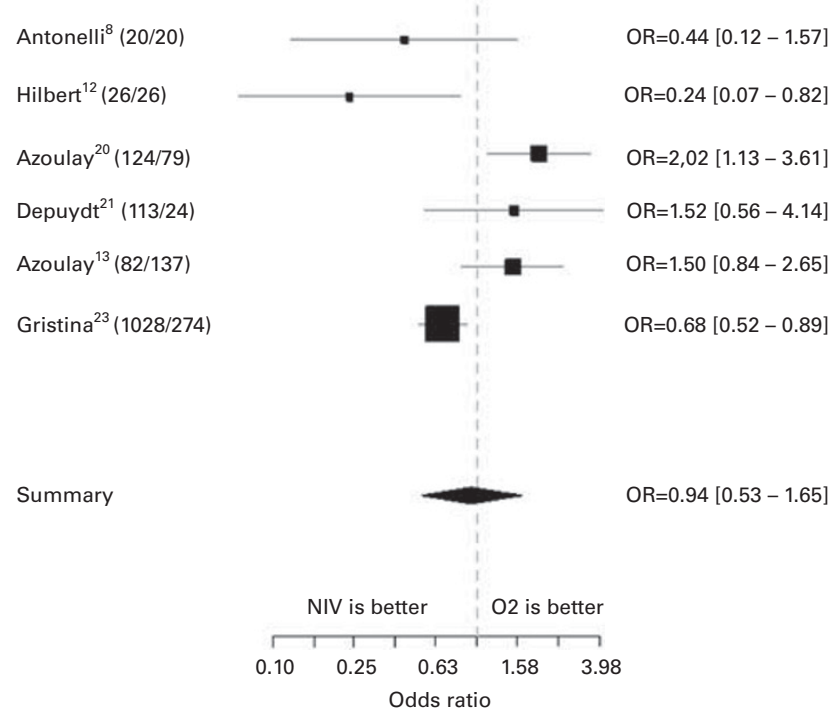

Figure 1 Outcomes associated with the in-ICU use of non-invasive mechanical ventilation in immunocompromized patients. Only cohort studies or trials reporting both patients receiving oxygen or NIV are reported. The authors are indebted to Dr Gerome Lambert (statistician) for devising this figure.

administered in control patients at a time where they would benefit from ICU admission and intubation. Along this line, studies in Table 1 report the frequent use of NIV in the wards, in patients with $\mathrm{PaO}_{2} / \mathrm{FiO}_{2}$ ratio $<200$. (5) Last, endpoints of such interventions can be considered as inaccurate. Indeed, ICU admission sometimes can be protective in hematology patients with mild to moderate organ dysfunction. Also, in-ICU prophylactic NIV could be a way to safely perform non-invasive or invasive diagnostic strategy. ${ }^{5,13,17}$

In summary, we believe that the following 10 reasons warrant additional randomized trials of prophylactic NIV in hematology patients with respiratory events. (1) No controlled trial on NIV use in only hematology patients is available; (2) no trial of prophylactic NIV in hematology patients is available; (3) only one randomized controlled trial from a single ICU has evaluated prophylactic NIV in 30 hematology patients; (4) benefit from NIV comes from studies with high mortality rates of intubated patients; (5) no study has formally distinguished prophylactic from curative NIV; (6) data from cohort studies suggest that early intubation offers survival benefits to hematology patients; (7) data from cohort studies raise concerns about late failure from NIV in hematology patients with ARF; (8) according to each hospital, technical requirements as well as nurse/physician to patient ratio may be insufficient to safely use NIV in patients with ARF; (9) conflicting results come from two studies on NIV outside of the ICU in hematology patients with respiratory events but no respiratory distress; (10) in patients who receive palliative NIV, cancer patients are the least likely to benefit. The study from Wermke is convincing about the lack of benefit from NIV in the hematology wards. In ICU patients, NIV should be evaluated in patients with hypoxemia but no respiratory distress. We believe that there is no place for
NIV in patients with hypoxemic ARF, respiratory distress, failure of oxygen and need for a ventilatory support. These patients should merely be intubated. The same is true for patients with criteria of acute respiratory distress syndrome or associated-organ dysfunction. Early (or prophylactic) NIV will need to demonstrate survival benefits at a time where ICU admission and mechanical ventilation are far from being futile interventions. In such a trial, great care should be taken to undertake appropriate diagnostic tests so as to identify the precise cause of the ARF, which can be a major confounding factor when analysing survival in immunocompromized patients with pulmonary involvement. ${ }^{12,13}$

\section{Conflict of interest}

The authors declare no conflict of interest.

\section{Acknowledgements}

This study was supported by a grant from the AssistancePublique Hôpitaux de Paris (AOM 04139) and the French Society for Intensive Care Medicine.

$$
\begin{array}{r}
\text { E Azoulay and V Lemiale } \\
\text { University Paris-7 Paris-Diderot, UFR de Médecine, } \\
\text { INSERM UMR 717, AP-HP, Hopital Saint-Louis, } \\
\text { Medical ICU, Paris, France } \\
\text { E-mail: elie.azoulay@sls.ap-hop-paris.fr }
\end{array}
$$

\section{References}

1 Azoulay E, Schlemmer B. Diagnostic strategy in cancer patients with acute respiratory failure. Intensive Care Med 2006; 32: 808-822.

2 Rabbat A, Chaoui D, Montani D, Legrand O, Lefebvre A, Rio $\mathrm{B}$ et al. Prognosis of patients with acute myeloid leukaemia admitted to intensive care. Br J Haematol 2005; 129: 350-357.

3 Afessa B, Tefferi A, Dunn WF, Litzow MR, Peters SG. Intensive care unit support and acute physiology and chronic health evaluation III performance in hematopoietic stem cell transplant recipients. Crit Care Med 2003; 31: 1715-1721.

4 Azoulay E, Alberti C, Bornstain C, Leleu G, Moreau D, Recher $\mathrm{C}$ et al. Improved survival in cancer patients requiring mechanical ventilatory support: impact of noninvasive mechanical ventilatory support. Crit Care Med 2001; 29: 519-525.

5 Azoulay E, Mokart D, Rabbat A, Pene F, Kouatchet A, Bruneel $\mathrm{F}$ et al. Diagnostic bronchoscopy in hematology and oncology patients with acute respiratory failure: prospective multicenter data. Crit Care Med 2008; 36: 100-107.

6 Brochard L. Noninvasive ventilation for acute respiratory failure. JAMA 2002; 288: 932-935.

7 Antonelli M, Conti G, Rocco M, Bufi M, De Blasi RA, Vivino $\mathrm{G}$ et al. A comparison of noninvasive positive-pressure ventilation and conventional mechanical ventilation in patients with acute respiratory failure. $N$ Engl J Med 1998; 339: 429-435.

8 Antonelli M, Conti G, Bufi M, Costa MG, Lappa A, Rocco M et al. Noninvasive ventilation for treatment of acute respiratory failure in patients undergoing solid organ transplantation: a randomized trial. JAMA 2000; 283: 235-241. 
9 Adda M, Coquet I, Darmon M, Thiery G, Schlemmer B, Azoulay E. Predictors of noninvasive ventilation failure in patients with hematologic malignancy and acute respiratory failure. Crit Care Med 2008; 36: 2766-2772.

10 Groeger JS, White Jr P, Nierman DM, Glassman J, Shi W, Horak D et al. Outcome for cancer patients requiring mechanical ventilation. J Clin Oncol 1999; 17: 991-997.

11 Depuydt PO, Benoit DD, Vandewoude KH, Decruyenaere JM, Colardyn FA. Outcome in noninvasively and invasively ventilated hematologic patients with acute respiratory failure. Chest 2004; 126: 1299-1306.

12 Hilbert G, Gruson D, Vargas F, Valentino R, GbikpiBenissan G, Dupon M et al. Noninvasive ventilation in immunosuppressed patients with pulmonary infiltrates, fever, and acute respiratory failure. $N$ Engl $J$ Med 2001; 344: 481-487.

13 Azoulay E, Mokart D, Lambert J, Lemiale V, Rabbat A, Kouatchet A et al. Diagnostic strategy for hematology and oncology patients with acute respiratory failure: randomized controlled trial. Am J Respir Crit Care Med 2010; 182: 1038-1046.

14 Wermke M, Schiemanck S, Höffken G, Ehninger G, Bornhäuser $\mathrm{M}$, Illmer $\mathrm{T}$. Respiratory failure in patients undergoing allogeneic hematopoietic SCT - a randomized trial on early non-invasive ventilation based on standard care hematology wards. Bone Marrow Transplant (e-pub ahead of print 19 September 2011; doi:10.1038/bmt.2011.160).

15 Truwit JD, Bernard GR. Noninvasive ventilation-don't push too hard. $N$ Engl J Med 2004; 350: 2512-2515.

16 Squadrone V, Massaia M, Bruno B, Marmont F, Falda M, Bagna $\mathrm{C}$ et al. Early CPAP prevents evolution of acute lung injury in patients with hematologic malignancy. Intensive Care Med 2010; 36: 1666-1674.
17 Antonelli M, Conti G, Riccioni L, Meduri GU. Noninvasive positive-pressure ventilation via face mask during bronchoscopy with BAL in high-risk hypoxemic patients. Chest 1996; 110: $724-728$.

18 Hilbert G, Gruson D, Vargas F, Valentino R, Chene G, Boiron JM et al. Noninvasive continuous positive airway pressure in neutropenic patients with acute respiratory failure requiring intensive care unit admission. Crit Care Med 2000; 28: $3185-3190$.

19 Principi T, Pantanetti S, Catani F, Elisei D, Gabbanelli V, Pelaia $\mathrm{P}$ et al. Noninvasive continuous positive airway pressure delivered by helmet in hematological malignancy patients with hypoxemic acute respiratory failure. Intensive Care Med 2004; 30: $147-150$.

20 Azoulay E, Thiéry G, Chevret S, Moreau D, Darmon M, Bergeron A et al. The prognosis of acute respiratory failure in critically ill cancer patients. Medicine (Baltimore) 2004; 83: 360-370

21 Depuydt PO, Benoit DD, Roosens CD, Offner FC, Noens LA, Decruyenaere JM. The impact of the initial ventilatory strategy on survial in hematological patients with acute hypoxemic respiratory failure. J Crit Care 2010; 25: $30-36$.

22 Meert AP, Berghmans T, Markiewicz E, Hardy M, Nayer N, Paesmans M, Sculier JP. Invasive mechanical ventilation in cancer patients. Prior non invasive ventilation is a poor prognostic factor. $J$ BUON 2011; 16: 160-165.

23 Gristina GR, Antonelli M, Conti G, Ciarlone A, Rogante C, Rossi $\mathrm{C}$ et al. Noninvasive versus invasive ventilation for acute respiratory failure in patients with hematologic malignancies: a 5-year multicenter observational survey. Crit Care Med 2011; 39: $2232-2239$. 